\title{
SOBERANIAS - UMA SUCESSÃO HISTÓRICA DE DEFINIÇÕES
}

\author{
Lúcia H. T. Viegas ${ }^{1}$
}

\begin{abstract}
Resumo: Este artigo apresenta diferentes significados que o termo soberania adquire, ao longo de uma sucessão histórica definida, ora como noção, ora como conceito. A dinâmica noção-conceito e vice-versa é dada em uma dialética construtivista - noções e conceitos sofrem desgaste, perdem significação, são reconstruídos, ou desaparecem. Da Grécia Antiga, passando por Jean Bodin até a contemporaneidade, observa-se que soberania é tratada mais no aspecto genealógico (termo) do que no aspecto epistemológico (noção-conceito). Soberania pode ser compreendida como o caráter essencial de um Estado autônomo historicamente determinado, capaz de exercer regências e jurisdições internas e externas para garantir a integridade da nação. O contexto empírico atual mostra a dificuldade de identificar e reconhecer as relações políticas de facto, que refletem a ação silenciosa e invisível de um sistema internacional pós-colonial, o qual se sobrepôs ao papel próprio dos Estados. $\mathrm{Na}$ atualidade, significações do termo soberania permanecem, assim, flutuantes enquanto dinâmica noção-conceito.
\end{abstract}

Palavras-Chave: soberania, definições, dinâmica noção-conceito

\begin{abstract}
This paper presents different significations that the term sovereignty acquires, within a defined historical succession, either as a notion, or as a concept. The notion-concept dynamics and vice versa comes about under a constructivist dialectic - notions and concepts are worn out, loose meaning, are reconstructed, or disappear. Beginning from Ancient Greece, going through Jean Bodin until contemporaneity, one can observe that sovereignty is examined more often under its genealogical aspect (term), than under its epistemological aspect (notion-concept). Sovereignty can be understood as the essential character of a historically determined autonomous State, capable of exercising commandment and jurisdictions, internal and external, to ensure the integrity of the nation. The current empirical context shows the-difficulty of identifying and recognizing de facto political relations, which reflect the silent and invisible action of a postcolonial international system that overlapped the proper role of the States. Nowadays meanings of the term sovereignty remain, therefore, fluctuating as a notion-concept dynamics.
\end{abstract}

Keywords: sovereignty, definitions, notion-concept dynamics

\footnotetext{
${ }^{1}$ Pesquisadora autônoma; Pós-doutorado em Estudos Estratégicos, Instituto de Estudos Estratégicos/ Universidade Federal Fluminense (INEST/UFF); Ex-analista da Financiadora de Estudos e Projetos (Finep). luciaviegas1@yahoo.com.

Muito agradeço a Ciro Moroni Barroso pelas discussões e pela cuidadosa revisão deste artigo.
} 


\section{Introdução}

É notória a variedade de uso e de significação do termo soberania presente na literatura acadêmica, nos discursos políticos, e nas críticas cotidianas das diferentes mídias.

Soberania é muitas vezes definida por noções ou por conceitos abstratos, idealizados, afastados da experiência; da mesma forma que Nação, Estado, e mesmo Governo. É comum a utilização de artigos definidos antes desses termos, em sentenças em que a soberania, a nação, 0 Estado e 0 governo se apresentam como sujeito, objeto ou complemento de uma determinada ação ou descrição, como que buscando um sentido universal para designa-los.

Na História da Filosofia e das Ciências, observa-se que os processos crítico-analíticos caracteristicamente se valem de noções a partir das quais os autores podem definir conceitos, para estabelecer disciplinas. Nas construções teóricas, entende-se noções como projetos, potenciais, expectativas, aproximações da significação de um termo, enquanto conceitos expressam significações bem definidas e compreendidas, resultantes da prática do conhecimento. Enquanto noções são flutuantes, conceitos são mensuráveis, objetivos, qualificáveis. Entretanto, ambos são historicamente determinados.

Noções são assim compreendidas como antecipações tipicamente associadas à cultura linguística, etnológica, comunicativa, e conceitos como resultantes de processos de significação articulados, acadêmicos, teóricos e científicos, de cada escola ou pensador.

Diferentes pesquisadores também tratam da necessidade de analisar as significações e transformações de significação de um conceito, sincrônica e diacronicamente, dentre os quais os historiadores Reinhart Koselleck e José D'Assunção Barros. O primeiro autor realça a necessidade de percepção da tensão permanente entre o "horizonte de expectativas" e o "espaço de experiência" (KOSELLECK, 2014, p. 307), na compreensão de um conceito. Os diferentes significados de um conceito, na perspectiva diacrônica, seriam o resultado de processos de mediação, recepção, apropriação e reinvenção de 


\section{Universidade Federal Fluminense Instituto de Estudos Estratégicos}

sentidos, associados a formações conceituais do passado, sincrônicas (Koselleck, 2014, 2020).

Para Barros (2016), as relações temporais e os processos de significação e ressignificação dos conceitos constituem construções coletivas que se superpõem às experiências individuais. Barros (2016, p. 67) também define noções como "quase conceitos", "imagens de aproximação de um determinado objeto de conhecimento" ainda não suficientemente delimitadas. Porém, observa-se que a flutuação dos sentidos de um termo, conforme tratada por Barros (2016) na definição de um conceito, igualmente se encontra presente nas formações históricas das noções. Noções são assim, parte integrante do processo histórico e cultural de estabelecimento de um conceito.

Um conceito resulta de uma epistemologia que cada autor constitui ao longo do processo de conhecimento. Uma noção não é o negativo ou o avesso de um conceito, mas uma significação inicial que permite um conceito surgir, constituindo assim disciplinas. Noções têm uma vida própria na história, na cultura e no linguajar da sociedade tão forte e significativa quanto um conceito; assim, não há uma hierarquia de valor entre noção e conceito, mas uma dinâmica.

Essa dinâmica noção-conceito e vice-versa pode ser observada tanto ao longo de uma sucessão histórica de significações do termo, quanto no âmbito de uma significação elaborada por um determinado pensador ou escola.

O texto está organizado como a seguir. Primeiramente, são apresentadas definições originárias de soberania, e analisada a dinâmica noção-conceito no pensamento de Jean Bodin. Optou-se por considerar definições do mundo grego como originárias para o mundo Ocidental. Este artigo não trata de acepções de soberania no mundo romano e em outras civilizações antigas que poderiam ser igualmente analisadas. Posteriormente, são apresentadas definições de soberania conforme alguns autores da época do lluminismo. A seguir, não abordando nessa oportunidade autores do séc. XIX e do início do séc. XX que discutem essa temática, são examinados noções e conceitos de soberania propostos por pensadores contemporâneos. Em seguida, encontram-se as considerações finais. 


\section{Noções e Conceitos de Soberania - Primórdios}

Os exemplos históricos das noções e conceitos de soberania representam as tentativas de compreensão dos diferentes pensadores quanto aos sentidos da ação de regência de príncipes, de classes/elites dirigentes, ou de instituições republicanas, conforme os Estados constituídos de cada nação. Ação esta exercida tanto em relação ao povo da nação quanto em relação a outros Estados.

Na Grécia antiga, segundo Vernant (2004), no que concerne às realezas micênicas, aproximadamente entre 1600 a 1000 a.C., o sistema palaciano, baseado na aristocracia guerreira, era bastante representativo como instrumento de poder, na medida em que permitia o estabelecimento de um controle Estatal sobre um extenso território, bem como possibilitava acumulação e concentração de riquezas, recursos e forças militares importantes, sob direção única. Além disso, permitia que essas realezas partissem de suas propriedades para - e mesmo se estabelecessem em territórios longínquos, para obtenção de metais e produtos de que o continente grego não dispunha. Essa organização social foi destruída pelas invasões dóricas, em cerca de 1000 a.C.

Pode-se observar que a forma política micênica representa uma soberania de facto, que desaparece e reaparece em diversos períodos posteriores, não apenas na Grécia, mas como uma forma antropológica hipoteticamente universal.

No devir histórico grego, a imagem de um rei - senhor todo poderoso, foi substituída pela ideia de funções especializadas, diferentes entre si, como forma de equilibrar as relações do rei com as diversas classes e o conjunto do corpo social, constituindo-se, assim, um cenário do qual poderia ser extraída uma noção inicial de soberania que deu origem à significação, junto à ideia de regência, que se estende até a atualidade.

No período helênico (a partir de 700 a.C. aprox.), de Homero e Hesíodo, as teogonias e cosmogonias "comportam, como as cosmologias que thes sucederam, relatos de gênese que expõem a emergência progressiva de um mundo ordenado. Mas são também [...] mitos de soberania". (VERNANT, 2004, 


\title{
Universidade Federal Fluminense Instituto de Estudos Estratégicos
}

p. 115). O autor apresenta um quadro no qual as teogonias gregas esboçam a imagem do mundo:

O universo é uma hierarquia de poderes. Análogo em sua estrutura a uma sociedade humana, não poderia ser corretamente representado por um esquema puramente espacial, nem descrito em termos de posição, de distância, de movimento. Sua ordem, complexa e rigorosa, exprime relações entre agentes; é constituída por relações de força, de escalas de precedência, de autoridade, de dignidade, de vínculos de domínio e submissão. Seus aspectos espaciais - níveis cósmicos e direções do espaço - expressam menos propriedades geométricas que diferenças de função, de valor, de classe.

Essa ordem não surgiu necessariamente em consequência do jogo dinâmico dos elementos que constituem o universo; foi instituída dramaticamente pela iniciativa de um agente.

O mundo é dominado pelo poder excepcional desse agente que aparece único e privilegiado, em um plano superior aos outros deuses: o mito projeta-o como soberano sobre o cume do edifício cósmico; é sua monarchia que mantém o equilíbrio entre as Potências que constituem o universo, fixando a cada uma seu lugar na hierarquia, delimitando suas atribuições, suas prerrogativas, sua parcela de honra. (VERNANT, 2004, p. 122123).

$\mathrm{Na}$ literatura acadêmica que trata do pensamento político no Ocidente, Jean Bodin (1533-1596) é comumente referenciado como o primeiro autor a conceituar soberania, conforme as definições apresentadas na obra os Seis Livros da República², publicada em 1576.

Bodin inicia o oitavo capítulo do Primeiro Livro propondo a conceituação de soberania.

\begin{abstract}
A soberania é o poder absoluto e perpétuo de uma República, que os Latinos chamam de majestatem, os Gregos de ákpav

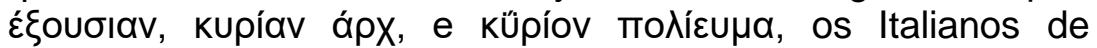
segnoria, palavra que eles usam para cada um em particular, e também para aqueles que manuseiam todos os negócios de uma República: os hebreus chamam de תזמד שכט , isto é, o maior poder de comandar. É aqui necessário dar forma a uma definição de soberania porque não há nenhum jurisconsulto ou filósofo político que a tenha definido, esse que é o ponto principal e o mais necessário de ser entendido no tratado da República. (BODIN, 1583, p. 122).
\end{abstract}

\footnotetext{
${ }^{2}$ República como referido por Bodin tem o sentido de res publica ou Estado constituído e não aquele utilizado a partir do séc. XVIII até os dias atuais (Estados republicanos).
} 
Na edição brasileira da obra, de 2011, traduzida por José C. O. Morel e revisada por José I. C. Mendes Neto, os três termos gregos são transliterados e definidos, respectivamente como: ákran éxusian - o mais elevado poder de influência; kyrían arkhê - o poder normativo senhorial; e kýrion políteuma administração pública senhorial. Igualmente, o termo hebreu tsimed shibeth envolve a ideia de domínio forte, proteção, como de um pastor pelas ovelhas.

A concepção de soberania do filósofo, jurista, parlamentar e professor Jean Bodin desperta tal deferência que sugere um maior detalhamento.

O conceito de soberania de Bodin traz pela primeira vez, pelo menos na França, a vinculação entre Estado e governo, marcada por uma ética de pertencimento do governante à República constituída. Os interesses privados do Príncipe não se sobrepõem aos interesses da República. O soberano é uma persona civilis, representante do Estado, não submetido a vontades exteriores. Regentes assumem o comando por determinado período de tempo, mas a República sempre permanece.

Entretanto, a autoridade uma vez conferida ao regente, deve ser absoluta, perpétua e indivisível. O caráter perpétuo da soberania é a própria definição do princípio de continuidade do Estado, resgatado a partir das Leis Fundamentais do Reino tal como na França de Bodin, que dão forma ao Estado, sem as quais nem o reino e nem o soberano existiriam. Essas Leis são admitidas por todos, distintas das leis ordinárias (Andrew, 2011; Bobbio, 1980; Riscal, 2001).

A definição de soberania de Bodin reflete o contexto da sociedade francesa do século XVI. Responde a demandas de paz civil em busca de uma identidade nacional e visa à consolidação do Estado nacional francês. A época de Bodin é marcada pela necessidade de uma instância capaz de moderar as relações e contradições da politica com as religiões: conflitos sangrentos, submissão dos reis ao papado; bem como moderar os conflitos entre classes aristocráticas, burguesas, artesãs, camponesas, e os poderes regionais dos diferentes burgos. Igualmente, pela necessidade de unificação das moedas, pesos e medidas no âmbito do território. Trata-se ainda, de um período de expansão comercial e econômica da França.

Bodin anseia fundamentar teoricamente a necessidade de unificação do Estado francês. 


\section{Universidade Federal Fluminense Instituto de Estudos Estratégicos}

Da mesma maneira que com vozes e sons contrários se compõem de uma doce e natural harmonia, também dos vícios e virtudes, das diferentes qualidades dos elementos, dos movimentos contrários, das simpatias e antipatias ligadas por meios invioláveis, se compõem a harmonia deste mundo e de suas partes. E, assim, também a República é composta de bons e maus, de ricos e pobres, de sábios e loucos, de prudentes e insensatos, de fortes e fracos, aliados àqueles que estão no meio entre uns e outros, de modo que o bem será mais poderoso que o mal, e concórdia prevalecerá sobre a discórdia. (BODIN, 1583, p. 1060).

\section{O pensamento de Bodin está embasado em um corpo teórico} estoico/platônico/aristotélico característico do Renascimento, a partir de leituras de Cícero, Dionísio de Halicarnasso e Plutarco. Assim, reproduz a visão helênica de um todo unificador maior do que cada parte, que efetua a coesão de uma dada realidade. Um todo, um mundo ordenado, como referido por Vernant (2014) nas lendas reais do povo Cita relatadas por Heródoto - o soberano é um personagem que se situa fora e acima das várias classes funcionais que compõem a sociedade,

porque ele representa todas, porque todas encontram igualmente nele a origem das virtudes que as definem, ele não pertence mais a nenhuma. [...] As atividades humanas que se opõem na sociedade se encontram integradas e unidas na pessoa do soberano. (VERNANT, 2004, p. 45-46).

Essa ordem grega é igualmente expressa, na forma de fragmentos, no pensamento do filósofo Heráclito de Éfeso (cerca de 544/1 a 484/74 a.C.) na descrição do logos, e pela filosofia estoica de Zenão de Cítium (c. 334-262 a.C.) e de Cleanthes (c. 331-232 a.C.) na acepção do tônos e do hegemonikôn ${ }^{3}$. Riscal (2001) sugere que Bodin estaria retomando a ideia do demiurgo, presente no Timeu de Platão4.

\footnotetext{
${ }^{3} \mathrm{O}$ logos heraclítico designa o sentido universal que rege todos os outros sentidos de experiência possível, o sentido universal unificador que faz a recondução dos pares de opostos em um processo supremo. Tônos é designado como uma força de coesão que dá estabilidade aos diversos tipos de corpos na natureza. Hegemonikôn é a fonte do princípio da regência universal que atravessa todos os reinos da natureza, inclusive o reino humano. Para aprofundamento, ver BERGE, D. O logos heraclítico: introdução ao estudo dos fragmentos. Rio de Janeiro: Instituto Nacional do Livro, 1969 e BARROSO, C. M. A Filosofia da Stoa: as teses de Zenão e Cleanthes. Rio de Janeiro: 7 Letras, 2019.

${ }^{4}$ A leitura de autores do Renascimento fundada na ideia do deus platônico parece ter perdido a visão abrangente de soberania do mundo helênico, como referenciado em Vernant (2004), no início deste item 2. Platão apresenta uma visão restrita do mundo grego conforme as cosmogonias e teogonias. $\mathrm{O}$ termo demiurgo originalmente significa artesão, aquele que trabalha as matérias-primas. O demiurgo platônico insere na matéria formas abstratas, incorpóreas. O estoico Zenão propõe uma versão sintética em termos físicos da tradição teogônica helênica (Barroso, 2019).
} 
Em tempos posteriores ao de Bodin, a conceituação de poder absoluto e perpétuo do autor é muitas vezes interpretada como uma noção de absolutismo, como oposta à divisão de poderes, ao republicanismo e à democracia liberal. Para Bodin, o poder absoluto significa uma instância de decisão governamental superior. Contudo, esse poder é limitado por leis divinas, da natureza e do Reino. Andrew (2011, p. 76) mostra, por exemplo, que Bodin reiterava que monarcas não deveriam tributar os próprios súditos sem o consentimento dos mesmos, "uma doutrina central para Locke e posteriormente para Rousseau, e para revolucionários americanos e franceses".

No que concerne à dinâmica noção-conceito implícita na definição de soberania de Bodin, essa dinâmica pode ser observada não apenas no enunciado da definição de soberania, quando parte de noções e explicita as significações dos termos latinos, gregos, italianos e hebreus, mas também a partir do contexto histórico-cultural vivenciado pelo autor, expresso nas expectativas dos franceses da época.

Quando Bodin anseia ver a República como a fonte do poder do indivíduo Regente, está formulando um conceito. Igualmente, quando indica que a definição de soberania por ele proposta é "o ponto principal e o mais necessário de ser entendido no tratado da República", "porque não há nenhum jurisconsulto ou filósofo político que a tenha definido", está estabelecendo uma nova disciplina jurídica: tendo sido definido um conceito, o edifício teórico pode ser então construído. Note-se que Bodin poderia ter utilizado o termo República, ou mesmo Estado, no lugar do termo Soberania para propor sua teoria - o conteúdo de significação da definição de Soberania de Bodin esteve presente no tempo histórico, desde os gregos antigos.

A definição de soberania de Bodin apresenta-se como a formulação de uma ansiada e necessária consciência cívica para a organização da sociedade, caracterizada no Renascimento, e que tem expressão maior no lluminismo do séc. XVIII. Essa é uma proposição que faz o coroamento da história monárquica europeia, da qual Bodin faz parte como burguês não opositor à monarquia. Pretende ainda, legitimar o indivíduo regente como soberano benevolente e esclarecido. Em que pese a oposição do jurista a governos mistos, para Bodin, Estados monárquicos podem ter governos democráticos ou 


\section{Universidade Federal Fluminense Instituto de Estudos Estratégicos}

aristocráticos, ou mesmo Estados democráticos podem ter governos monárquicos ou aristocráticos. O pensamento teórico de Bodin vem a ser assim precursor mais abrangente da ideia de Estado civil e de contrato social, quando, por exemplo, sugere que não apenas chefes de Estado, mas também funcionários servem ao interesse público e não a interesses pessoais, bem como ao incluir lares e colegiados na República. O texto de Bodin seria uma Carta ou Escritura, que estabelece o equivalente a um acordo ou contrato social de soberania cívica, que inspira repúblicas até os dias atuais.

Assim como o navio não é mais do que madeira informe quando se the tira a quilha, que sustém o costado, a proa, a popa e o convés, também a República, sem poder soberano, que une todos os membros e partes da mesma, e todos os lares e colégios num só corpo, não é mais República. (BODIN, 1583, p. 12).

Nicolau Maquiavel (1469-1527) não trata diretamente da noção, ou mesmo conceito, de soberania, como após proposto por Bodin e Hobbes. Maquiavel propõe um governante capaz de estabelecer um Estado coerente e unificador para uma nação, seja esta de pequena ou grande extensão. Portanto, um governante (Príncipe) capaz de exercer uma ação de liderança, ora conciliadora, ora audaciosa, ora prudente, para evitar a pulverização da nação.

O sentido moral e politico, segundo Maquiavel, seria a virtú - noção indefinida que, a rigor, não é estranha à concepção de uma soberania que conta com reconhecimento nas classes da sociedade. A virtú maquiaveliana tem a característica de um processamento, ou práxis, ou ainda de uma coletânea de métodos para a obtenção de uma governança a que uma nova liderança deve recorrer para adquirir legitimidade e capacidade de regência.

Maquiavel escreve no momento de invasões e subdivisões na Itália, em que os Estados estão continuamente sendo constituídos e desfeitos. Existe na Itália a necessidade de um líder, de um governante bem-sucedido, reconhecido, que possa ocasionar a unificação da nação, sem a presença de um Estado já formado. Esse líder não tem nem o perfil de generalconquistador, nem de um líder civil que tenha uma legitimidade já reconhecida pelo povo da nação. É a partir da sua capacidade de regência e virtú, que esse líder consegue estabelecer as bases para um Estado da Nação. 
Conforme o autor, na dialética da História, a constituição dos meios, i.e., da capacidade de governo, seria anterior e mais necessária que os fins, estes o estabelecimento de uma república estável e soberana. Para Bodin, essa finalidade, a da soberania, seria antes de mais nada necessária, para se justificar os meios, que seriam o governo. Pode-se inferir assim uma simetria entre as teses de Maquiavel e Bodin, de modo que sendo consideradas opostas na história sincrônica, podem ser dadas como complementares na história diacrônica.

O pensamento filosófico de Thomas Hobbes (1588-1679) inicialmente se propõe a estabelecer a diferença entre o estado natural do homem e o estado civil. No estado natural, ao buscarem por desejos, apetites e paixões, os homens tornam-se egoístas e entram em conflito. Contudo, procurando a preservação da vida quando esta se encontra ameaçada, os homens são obrigados a entrar em sociedade. A organização que surge do acordo entre os homens não é natural como entre os animais (abelhas ou formigas), mas artificial. Assim, guiados pela razão e pelo instinto de conservação, os homens são levados a estabelecer contratos e pactos entre si. Como estes são artificiais e precários, para assegurar a paz, cada homem submete a vontade própria à vontade de um único governante, ou de uma assembleia determinada, os quais serão soberanos, conforme a acepção hobbesiana de soberania.

Hobbes analisa essas questões na obra Leviatã ou Matéria, Forma e Poder de um Estado Eclesiástico e Civil, publicada em 1651. Na introdução dessa obra, o filósofo estabelece analogias entre a natureza humana e o funcionamento de máquinas autônomas e, entre estas últimas e a ação humana de construção do Estado Civil (Common-Wealth). Utilizando essas analogias apresenta uma definição para soberania. Observe-se que a obra foi publicada poucos anos após a execução de Charles I, em 1642, pelo parlamento britânico composto por integrantes da abastada classe média emergente, no contexto de uma guerra civil para retirada do controle do Estado das mãos da monarquia.

Pela arte é criado aquele grande Leviatã a que se chama Estado, ou Cidade (Civitas), que não é senão um homem artificial, embora de maior estatura e força do que o homem natural, para cuja proteção e defesa foi projetado. E no qual a 


\section{Universidade Federal Fluminense Instituto de Estudos Estratégicos}

soberania é uma alma artificial, pois dá vida e movimento ao corpo inteiro; os magistrados e outros funcionários, judiciais ou executivos, juntas artificiais; a recompensa e o castigo (pelos quais, ligados ao trono da soberania, todas as juntas $e$ membros são levados a cumprir o seu dever) são os nervos, que fazem o mesmo no corpo natural; a riqueza e prosperidade de todos os membros individuais são a força; Salus Populi (a segurança do povo) é seu objetivo; os conselheiros através dos quais todas as coisas que necessita saber lhe são sugeridas, são a memória; a justiça e as leis, uma razão e uma vontade artificiais; a concórdia é a saúde; a sedição é doença; e a guerra civil é morte. Por último, os pactos e convenções mediante os quais as partes deste Corpo Político foram criadas, reunidas e unificadas assemelha-se àquele Fiat, ao Façamos o homem proferido por Deus na Criação. (HOBBES, 1983, p. 5).

Para Hobbes, seguindo Bodin, os atributos fundamentais da soberania são o caráter absoluto e a indivisibilidade. De acordo com Bobbio (1980, p. 9798), a tese política de Hobbes considera que "o vínculo que os súditos têm com relação às leis positivas não é da mesma natureza do que prende o soberano às leis naturais". Essa tese pressupõe a existência de duas instâncias legais: as leis naturais e divinas, que são "interiormente obrigatórias", dadas à consciência ética individual; e as leis positivas, que são seculares, aplicadas pela "força do poder comum", e assim "exteriormente obrigatórias". Entretanto, diferentemente de Bodin, Hobbes entende que o direito de propriedade, que seria um direito civil, deveria pertencer à tutela do Estado.

\section{Noções e Conceitos de Soberania - Iluminismo}

John Locke (1632-1704) e os autores do Iluminismo, principalmente na França, Charles-Louis de Secondat, Barão de Montesquieu (1689-1755) e Jean-Jacques Rousseau (1712-1776), desenvolvem as respectivas teses republicanas e liberais tendo como referência as noções de contrato social ou constitucionalismo.

Para Locke e Rousseau, os homens no estado de natureza seriam livres, gregários e cooperativos como necessidade cívica (i.e., não pela forma econômica, como preconizado por Marx e Engels), portanto estariam propensos a entrar em acordo sobre um determinado Contrato Social. 
De acordo com Locke, o poder de entrar em acordo seria um primeiro poder, legítimo, soberano. A sociedade funda o Estado por meio de um contrato, que será sempre referendado pelo povo dessa nação. Esse primeiro poder constitui o segundo poder legítimo, que é o Estado, na forma republicana liberal. A figura do Regente está presente em termos formais, mas divide o exercício desse poder, ou soberania, com várias instâncias governamentais. É o Estado constituído que dá a legitimidade aos governantes.

Assim como Locke, Montesquieu poucas vezes faz uso do termo soberania. Na obra Do Espírito das Leis, de 1748, Montesquieu estabelece a distinção primordial entre 3 tipos de Estados ou formas de governo: despóticas, monárquicas e republicanas. As repúblicas podem ser senatoriais (aristocráticas) ou baseadas em assembleias democráticas, mas não monarquias. As monarquias têm uma legitimidade própria, o que é diferente dos regimes despóticos. O autor entende a noção de Espírito das Leis como a análise do conjunto empírico social, observando as variações geográficas, naturais, socioeconômicas, e mesmo espirituais das sociedades.

Na obra O Contrato Social ou Princípios do Direito Político, publicada em 1762, Rousseau apresenta uma reflexão filosófica sobre uma forma de governo que melhor afirme a liberdade individual de todos os cidadãos, sugerindo o contrato social acordado por todos, como modo de preservação mútua do indivíduo e da sociedade. O autor denomina de soberano, ao regente que representa uma vontade geral, a qual visa ao bem comum, sendo a soberania a atuação desse regente tendo em vista o interesse coletivo de todos os cidadãos.

Note-se que as definições de soberania até aqui apresentadas se constituem como formulações conceituais caracteristicamente idealistas (platônicas, utópicas), que não necessariamente resultam de processos políticos de ação governamental. Seria oportuno mencionar brevemente que Marx e Engels, e os outros autores socialistas do séc. XIX tendem a uma leitura crítica do Estado republicano liberal burguês nos termos de que seria uma utopia impraticável. Ainda que as concepções políticas dos autores iluministas expressem claramente o estágio de desenvolvimento social da época, o Estado liberal não é atingido devido às contradições de classe que 


\section{Universidade Federal Fluminense Instituto de Estudos Estratégicos}

resultam da divisão social do trabalho - as diferentes classes têm demandas e formas de consciência desiguais sobre a República a ser constituída.

Cabe ainda destacar a questão do deísmo. Os autores do Renascimento e os protestantes do lluminismo estão preocupados em reconhecer Deus e as leis divinas, porém entendem que essas leis não devem interferir nos estatutos cívicos e políticos. Igualmente, não aceitam a autoridade papal ou religiosa sobre esses estatutos. A maioria dos autores desses períodos tem suas vidas pessoais profundamente afetadas pelo dilema entre protestantes e católicos, quando os protestantes se inclinam para os regimes contratuais e os católicos para o absolutismo.

\section{Noções e Conceitos de Soberania na Contemporaneidade}

$\mathrm{Na}$ primeira metade do séc. XX, a literatura acadêmica, naquelas escolas sob inspiração marxista, na Filosofia e nas Ciências Políticas, não trata de soberania como tema explícito de estudo. Contudo, uma noção de soberania está implícita para a constituição de um Estado civil, que é resultado do planejamento econômico estatal e da redenção das massas sociais periféricas ou excluídas. Além disso, a forma da assembleia com voto majoritário, que está na origem da revolução soviética de 1917, expressa uma revalidação da noção de soberania, sob uma acepção já conhecida.

A partir dos anos 1960, muitos estudos sobre o tema soberania, na literatura especializada, de caráter multidisciplinar, têm como ponto central a constituição histórica das formas de regência em um mundo caracterizado pela participação cada vez mais reduzida dos Estados-Nações. Por exemplo, na visão do antropólogo Clifford Geertz, considerar um Estado na condição de regente de um território e de uma população, de representante de uma forma racional de governança unificada, em países multilinguísticos, multiétnicos e multirreligiosos, seria uma ficção da modernidade (Geertz, 2004). O professor de Relações Internacionais Hideaki Shinoda examinou noções e conceitos de soberania na história ocidental por uma abordagem genealógica, nas perspectivas sincrônica e diacrônica, e apontou a dificuldade de se encontrar uma noção política mais controversa do que a de soberania na produção 
acadêmica contemporânea. Para Shinoda (1997), nos dias atuais, o conceito de soberania nacional é um "conceito revolucionário", na medida em que manifesta uma insatisfação da sociedade com o status internacional da nação, enquanto que o conceito de soberania constitucional representa uma aceitação da ordem internacional vigente. Segundo o autor, "o sistema internacional" atual é caracterizado por economia de mercado globalizado, expansão das atividades de instituições internacionais, desenvolvimento acelerado de novas tecnologias, conflitos entre minorias e governos centrais e crescente preocupação com direitos humanos.

As análises contemporâneas sobre os significados de soberania fundamentaram-se, inicialmente, nas ideias do filósofo Michel Foucault (19261984), um dos autores que desenvolveu o tema da inclusão da vida biológica nos mecanismos e nos cálculos do exercício do poder estatal (Agamben, 2007), denominando-a de biopolítica e de biopoder - o controle estatal estabelecido sobre as diferentes esferas da vida (Mbembe, 2018). Foucault (1976) argumenta que a racionalidade que define o que denomina poder moderno (biopoder) é diferente daquela do poder soberano - enquanto este é caracterizado por um direito sobre a vida e a morte (direito de matar ou de deixar viver), o poder moderno compreende uma relação produtiva com a vida, no sentido de administrar os corpos, de gerir a vida de forma interessada e calculista. Na concepção de Foucault, soberania é percebida como exercício de poder no sentido legal e normativo.

Hansen e Stepputat (2006) argumentam que o predomínio da visão foucaultiana em muitos dos estudos sobre o tema soberania na Antropologia criou impasses:

Em muitos aspectos, o triunfo de uma visão foucaultiana de poder criou um impasse em si mesma. Se o poder é disperso por toda a sociedade, em instituições, disciplinas e rituais de subjetivação, como nós, por exemplo, respondemos pela proliferação de discursos legais com base na ideia popular generalizada do estado como um centro da sociedade, um legislador central e um juiz? Como entendemos as mitologias populares do poder, da corrupção, do segredo e do mal como provenientes de certos centros, pessoas, ou domínios escondidos? Como interpretamos como a violência destrói os laços sociais, mas também produz autoridade informal? Como podemos compreender a guerra como uma lógica totalizante da vida e da sociedade, como apontado por Foucault na década de 1970? (HANSEN; STEPPUTAT, 2006, p. 296). 
De acordo com Hansen e Stepputat (2006), esses questionamentos foram superados pela proposta de Giorgio Agamben (1942-), autor que propõe corrigir a visão de Foucault quando afirma que poder soberano já é intrinsecamente biopolítico, na medida em que considera a "vida nua" ${ }^{5}$ como ponto de partida para a ordem política. Para Agamben (2007), soberania está associada ao ordenamento jurídico-institucional, frequentemente comportando o estabelecimento de estados de exceção para justificar a violência e decisões de um poder soberano. As análises de Han (2020) sobre a visada foucaultiana apontam que "a biopolítica é a técnica de governança da sociedade disciplinar, mas é totalmente inadequada para o regime neoliberal, que antes de tudo, explora a psique" (HAN, 2020, p. 35).

A política da morte ou necropolítica, termo cunhado pelo filósofo camaronês Achille Mbembe (1957-), examina as formas em que a morte se apresenta na biopolítica. Mbembe (2018) indica que a acepção de Foucault sobre biopoder não explica suficientemente "as formas contemporâneas que subjugam a vida ao poder da morte" (p. 71), as quais estão além da "inscrição de corpos em aparatos disciplinares" (p. 59), porém circunscritas em zonas de exceção e de morte, tornando-se o exercício último de dominação e a principal forma de resistência. O filósofo exemplifica, citando a situação da Palestina nos últimos anos - uma ocupação colonial tardia, em que condições de assujeitamento são dadas particularmente pela combinação entre o disciplinar, a biopolítica e a necropolítica.

Conforme Mbembe (2018), soberania expressa predominantemente 0 direito de matar.

A expressão máxima da soberania reside, em grande medida, no poder e na capacidade de ditar quem pode viver e quem deve morrer. Por isso, matar ou deixar viver constituem os limites da soberania, seus atributos fundamentais. Ser soberano é exercer controle sobre a mortalidade, definir a vida como a implantação e manifestação de poder. (MBEMBE, 2018, p. 6)

\footnotetext{
${ }^{5}$ Agambem (2007) observa a existência de um único termo para designar vida nos diversos idiomas da sociedade ocidental atual, diferentemente da Antiguidade grega. Os gregos denominavam bios a forma pela qual a vida é vivida e zoe o fato biológico da vida. Agamben denomina "vida nua" a vida associada ao valor do termo grego zoē, que privilegia a dimensão biológica em relação à dimensão da qualidade da vida vivida.
} 
A pesquisa de Weber (1995) trata das inúmeras e multíplices formas de soberania que coexistem no contexto político atual, e mostra que os significados do termo soberania são estabelecidos por práticas políticas fundadas em práticas discursivas de lideranças estatais. A autora parte da premissa de que a fronteira soberania-intervenção é o verdadeiro locus do Estado, "desconstruindo" definições de soberania histórica e aprioristicamente estabelecidas, na teoria e na prática. Tomando assim como chave analítica a díade soberania-intervenção em diferentes momentos históricos, Weber (1995) indica que a intervenção se constitui em uma prática que preenche 0 significado da soberania estatal. Pela legitimação da intervenção, fronteiras nacionais são desenhadas, e demarcados interesses de âmbito interno e em relação a outras nações.

Para Krasner (2009), Estados soberanos ainda persistem. As estruturas constitucionais continuam preservadas, apesar das mudanças tecnológicas tornarem praticamente impossível o controle do fluxo de bens, serviços e capitais, lícitos e ilícitos, no âmbito das fronteiras geográficas de uma nação. Soberania, conforme o autor, significa a condição de autoridades políticas de diferentes Estados encontrarem-se livres e não coagidas para subscrever acordos internacionais que considerem atrativos e de interesse nacional.

A maioria das pesquisas fundadas no conceito de biopolítica parece estar sustentada no dualismo simples de uma definição de poder, como exercício da vontade de um soberano racional, indivíduo ou instituição, que decide ou não limitar a liberdade, a vida ou a morte de cada indivíduo integrante de uma nação. Esses estudos não apreciam a possibilidade de que o poder de um soberano possa, de início, ser determinado por estruturas sociais que se fazem presentes de forma inconsciente na vontade desse poder estatal. São diversos os exemplos históricos em que governantes de regimes considerados "fortes" (portanto, não exatamente ditaduras) têm sua soberania reconhecida pelas classes da nação.

A realidade atual em que um poder político é exercido de forma não explícita, dissimulada, por um poder de classe não facilmente identificável, mostra uma situação diferente que requer o reposicionamento de muitas das noções e conceitos de soberania até então apresentados, conforme é 


\section{Universidade Federal Fluminense Instituto de Estudos Estratégicos}

examinado nas pesquisas de Dreifuss (1987, 2004), Hudson (2011), Glattfelder (2010), Compston (2013), Lyon (2018), Perkins (2006), Viegas e Bomtempo (2012) e Vitali, Glattfelder e Battiston (2011), entre outros.

A sociedade contemporânea, dita pós-colonial, pós-capitalista, neofeudal, é determinada pela autoridade de um projeto político baseado no planejamento de longo prazo, gerido principalmente por proprietários de organizações financeiras, e não por uma estrutura econômica nos moldes de uma sociedade capitalista tradicional. Esse projeto, com objetivo de exercer domínio, comando e controle sobre uma realidade social em escala internacional, inclui o controle societário de empresas transnacionais; o controle do alto-escalão de governos de alguns Estados; a capacidade de emissão de moeda; a declaração e a efetivação de guerras; o controle do desenvolvimento de pesquisas científicas e tecnológicas e da propriedade de tecnologias; o uso de linguagens pré-fabricadas; a operacionalização de psicopolíticas e de políticas de vigilância, estas mediante uso indiscriminado e irrestrito de tecnologias proprietárias de informação e comunicação (TICs).

Cabe aqui enfatizar as análises seminais do professor René Dreifuss (1945-2003). Conforme Dreifuss (1998, 2004), os dois protagonistas principais desse desenvolvimento histórico neofeudal são as "corporações estratégicas" com "tecnobergs" subjacentes e os Estados nacionais. No dizer do pesquisador, "corporações estratégicas" são empresas que se estruturam para manter a capacidade de inovação, capazes de embutir os seus trunfos, isto é, as facilidades intangíveis de produção que permitem geração de riqueza material, bem como as suas descobertas (invenções/inovações), nos processos de produção e nos produtos finais de um grande número de sistemas controlados por outros agentes (e.g., Intel, Microsoft). Tais corporações podem não dispor de matéria-prima, mas sabem o que fazer com ela; podem não ter as instalações produtivas, mas sabem fazê-las funcionarem melhor. "Tecnobergs" ${ }^{6}$ (termo cunhado pelo professor entre 1987 e 1988) ou

\footnotetext{
${ }^{6}$ Acrônimo de "Teleinfocomputrônica satelital" - tecnologias de comunicação e informação, incluindo a "articulação de saberes e potenciais de pesquisa e análise, como aqueles contidos na elaboração de um Grid" (p. 37); Engenharia de novas concepções - engloba as sínteses de biomateriais, entre outros, as gelatinas inteligentes, as fibras compostas, as novas cerâmicas e vidros, as novas ligas, as combinações de processos orgânicos e inorgânicos; Cognição - "incluindo o conjunto gnosetecnológico de apreensão e de um manejo da realidade real e virtual, [...], aplicada ao aprendizado, planejamento, desenho, desenvolvimento e adestramento para a produção, aos assuntos militares e de gestão societária, dentro e
} 
"montanhas tecnológicas" referem-se ao conjunto entrelaçado de conhecimento e tecnologias inovadoras que sustenta e é sustentado pelas "corporações estratégicas". Os instrumentos de poder das corporações estratégicas advêm da capacidade política estabelecida com a presença prévia articulada dessas empresas em diferentes nações, na capacidade militar, na vida cultural e na dinâmica econômica e política. Os escritos de Dreifuss fornecem material empírico e interpretativo o qual permite antecipar as análises de autores que discutem a condição de uma sujeição generalizada experimentada pelas sociedades contemporâneas.

Hansen e Stepputat (2006) mostram como paradoxal no séc. XXI, considerar um Estado-Nação, na acepção tradicional, como locus privilegiado de um poder soberano, quando países do Oriente Médio e do Norte da África são invadidos pelos Estados Unidos e nações amigas. Os autores propõem duas significações para soberania: uma soberania legal, i.e., o direito legitimado de governar, fundamentada formalmente em lemas de regência e legalidade, e uma soberania de facto, ou o direito sobre a vida, manifestada pela impunível capacidade de matar, castigar, disciplinar, proteger, reabilitar e reconstruir, fundada na violência, e projetada e exercitada para gerar medo, lealdade e legitimidade.

Empresas transnacionais, o soft power da rede global de organizações não-governamentais (ONGs) e de comunidades na internet, bem como a proliferação de conflitos étnicos na era pós Guerra Fria parecem prejudicar a naturalidade da ideia de soberania nacional nos anos 1990. As consequências do 9/11 tornam claro que soberania nacional, guerra, e regimes de segurança ainda permaneceram como o núcleo duro dos Estados modernos. Torna-se ainda evidente, porém, que a nova ameaça à ordem mundial estabelecida viria de forças de difícil conceituação - definitivamente de redes globais altamente móveis, evanescentes [...], que deixam o poder institucionalizado altamente vulnerável. (HANSEN; STEPPUTAT, 2006, p. 296).

Com efeito, Mbembe (2018) observa que, especialmente em lugares que dispõem de recursos naturais valiosos, cada vez menos uma guerra ocorre

fora dos limites nacionais, e à criação de ambientes perceptivos e experimentais com texto e animação" (p. 38-39); Nanotecnologia - para a busca de informações sobre o corpo humano e seu contexto, ou armazenamento de arquivos com centenas de informações pessoais; Optoeletrônica - incluindo os neurochips; Biotecnologia - incluindo bioinformática, biorobótica, conexões com novos materiais, medicamentos inteligentes, próteses; Energias alternativas e novas; Robótica; Genômica; e Serviços inteligentes. (DREIFUSS, 2004). 


\section{Universidade Federal Fluminense Instituto de Estudos Estratégicos}

entre exércitos de dois Estados soberanos, mas "é travada por grupos armados que agem por detrás da máscara do Estado contra grupos armados que não têm Estado, mas que controlam territórios bastante distintos" (p. 60); ambos os lados tendo populações desarmadas como alvo. "Máquinas de guerra estão implicadas na constituição de economias locais ou regionais altamente transnacionais" (p. 57).

No contexto de territórios e fronteiras informacionais, Zuboff (2018), em estudo que examina sistemas e ações institucionais interconectados e mediados por computador (e.g., big data, machine learning, drones), aponta, igualmente, a existência de uma nova lógica de acumulação e de novas relações sociais - o "capitalismo da vigilância", que Han (2020, p. 23) denomina de "era da psicopolítica digital". Para Zuboff (2018), o "capitalismo da vigilância" substitui os contratos, o Estado de direito e a confiança social pela "soberania do Big Other". O Big Other constitui "um ubíquo regime institucional em rede, que registra, modifica e mercantiliza a experiência cotidiana, desde o uso de um eletrodoméstico até seus [sic] próprios corpos, da comunicação ao pensamento, tudo com vista a estabelecer novos caminhos para monetização e lucro" (ZUBOFF, 2018. p. 43-44). Constitui ainda, um poder legitimado de controle e vigilância, quase sempre "livre de detecção ou sanções" (ZUBOFF, 2018, p. 49). "Ao contrário do poder centralizado da sociedade de massa, não existe escapatória em relação ao Big Other. Não há lugar para estar onde o Outro também não está" (ZUBOFF, 2018, p. 44). Han (2020) observa que a partir do big data é possível extrair não apenas psicogramas individuais e coletivos, mas também o "psicograma do inconsciente" (p. 36), passível de uso para promoção de padrões coletivos de comportamento, sem que o indivíduo tenha consciência do processo. "O poder soberano se exprime como direito de expor e tomar" (HAN, 2020, p. 46).

Nesses termos, o arquétipo de soberania de um Estado-Nação fundado na regência, autoridade, legitimidade e controle sobre territórios geográficos e corpos, inseridos em cartas nacionais, foi suplantado por uma construção baseada em pactos e composições nem sempre explícitos, que capacita empresas privadas, particularmente "corporações estratégicas" (financeiras ou não) e "tecnobergs" associados para neutralizar, substituir, mesmo desafiar, as funções do Estado soberano. 
Em um mundo globalizado, pós-colonial, neofeudal, essas substituições das soberanias tradicionais são delineadas por contornos intencionais, porém velados, de um grupo seleto de dirigentes de organizações nacionais e transnacionais. Seguem alguns exemplos dessas substituições de soberanias, ou de soberanias ausentes:

a terceirização de serviços e o uso de equipamentos vitais de infraestrutura, informação e telecomunicação, energia e saúde, de propriedade de grandes empresas privadas, transnacionais na maioria;

- o financiamento de projetos nacionais de desenvolvimento por países mais desenvolvidos, implementados por empresas privadas e organizações não governamentais, muitas vezes com pessoal externo, em nome de EstadosNações soberanos;

a crença de que as ações políticas de um líder formal atendem primordialmente aos interesses nacionais próprios;

- o desenvolvimento de redes de segurança (proteção e vigilância) por agências internacionais vinculadas a agências militares e a empresas privadas, nacionais e estrangeiras, via contratos e outros mecanismos de coordenação;

- as práticas de cerceamento tecnológico e a adoção de paradigmas tecnológicos nem sempre correspondentes a demandas nacionais prioritárias; e

- a linguagem, os enunciados, os valores, as crenças veiculados pela grande mídia, e também nas práticas discursivas de lideranças internacionais, indivíduos e instituições.

Assim, ao serem interrogadas as premissas de autonomia de EstadosNações, observa-se que significações do termo soberania permanecem flutuantes enquanto dinâmica noção-conceito na contemporaneidade.

\section{Considerações Finais}

De modo geral, seria necessário indagar se noções e/ou conceitos de Soberania, Nação e Estado podem ser examinados separadamente. Exemplos históricos mostram que os Estados surgem como consequência do processo 


\section{Universidade Federal Fluminense Instituto de Estudos Estratégicos}

de formação da Nação, conforme cada caso. O Estado historicamente constituído é o garantidor da nação, das necessidades da nação, representa a soberania dessa nação. Portanto, as noções-conceitos de soberania confundem-se com as próprias noções-conceitos de legitimação da Nação e do Estado. Essas noções e conceitos trazem sempre embutidas em si-mesmas a ideia de relações políticas e de atos de regência, como nas definições apresentadas. Contudo, diferentes dimensões de Soberania, Nação e Estado coexistem do ponto de vista empírico.

Estado e soberania são inseparáveis e simultâneos conforme aparecem reiteradamente nos exemplos e definições históricos. Para Figueiredo (2015), soberania é definida como a própria existência de um Estado como tal. De acordo com Santos (2016), a afirmação da identidade nacional constitui a base da soberania das nações, na medida em que fronteiras, antes de serem jurídicas, são culturais e não delimitadas. Com efeito, observa-se que uma determinada unidade linguística frequentemente aparece como fator de desejo de unificação nacional.

Segundo Barroso $(2018,2012)$, soberania, primordialmente, seria a própria ideia da nação ou da fundação da nação sendo reiterada, simbólica e efetivamente. Como celebração de identidade mitológica, verifica-se até os dias atuais, em todos os países do mundo, paradas militares, hasteamento de bandeiras e hinos patrióticos, nas datas de fundação de monarquias e repúblicas, de independências e revoluções, preenchendo o imaginário dos habitantes de uma nação. Segundo o autor, as nações primordiais seriam resultantes de vitórias alcançadas em concurso de guerras, e o Estado, não apenas o resultado dos desejos, ambições ou anseios dos povos. A vida dos povos requer uma Regência, toda vez que as tribos, condados, praças fortes, se encontram em uma unidade territorial. Essas demandas partem do conjunto social, de estruturas sociais que levam os indivíduos, reis, generais, políticos, soldados, à ação, sem que eles tenham consciência plena do que fazem. Com o desenvolvimento do Estado da nação, as tarefas da soberania, enquanto poder e regência, passam a ser econômicas, jurídicas, diplomáticas, científicas e tecnológicas; descoberta e preservação de recursos naturais; 
desenvolvimento dissuasivo de forças navais, terrestres e aéreas, entre outras. Soberania passa a expressar a própria administração e defesa da nação.

Nesses termos, soberania pode ser compreendida, ora no valor de noção, ora no valor de conceito, para designar o caráter essencial de um Estado autônomo historicamente determinado, capaz de exercer regências e jurisdições internas e externas para garantia da existência da nação enquanto tal.

Ao trazer essa definição de soberania para a contexto empírico dos dias atuais, surgem então algumas perguntas. Como preservar a existência de um Estado autônomo, frente à dificuldade de se identificar e reconhecer as intrincadas relações de poder político e de controle, que refletem a ação silenciosa e invisível de um sistema internacional pós-colonial, o qual se sobrepõe ao papel próprio do Estado? Essa questão abre perspectivas para estudos futuros sobre significados e usos do termo soberania na contemporaneidade.

Em muitos dos estudos que se tornaram referência no tema soberania (e.g., Bodin, Rousseau, Agamben), o significado de soberania é examinado isoladamente, na qualidade de termo ou de noção ou de conceito. Soberania é tratada mais no aspecto genealógico (termo) do que no aspecto epistemológico (noção-conceito). Todavia, a significação do termo soberania requer uma explicitação epistemológica caso a caso. O termo soberania passa assim por muitas variações de sentido, históricas, filológicas, filosóficas e epistemológicas.

Haveria necessidade de uma definição de soberania segundo um conceito disciplinar, universal, ou mesmo histórico? Em 1969, o cientista político e professor Ernst Haas categoricamente declarou "Eu não uso o conceito de modo algum e não vejo necessidade de usá-lo"7. Existiria um excesso de idealismo em torno do termo soberania?

Observa-se que acepções de soberania mantidas enquanto descritivas, auxiliares, servem muito mais à compreensão, à interpretação, à cultura histórica, do que se fossem enquadradas como conceitos críticos, analíticos, definidos. Uma definição de soberania não pode ser compreendida somente de

\footnotetext{
${ }^{7}$ HAAS, E. Letter to the Editor, Journal of Common Market Studies, v. 8, n. 1, p. 70, set. 1969.
} 


\section{Universidade Federal Fluminense Instituto de Estudos Estratégicos}

um ponto de vista ontológico e nem somente a partir da análise de práticas discursivas. Conceitos e noções têm definições históricas, localizadas estruturalmente, vigentes em determinado tempo, em uma cultura. Conforme as leituras empiristas e antropológicas, noções comuns nem sempre exigem uma evolução como conceito definido. Uma definição universal de soberania, válida em todo e qualquer contexto histórico-cultural não é possível e nem necessária.

A dinâmica noção-conceito é dada em uma dialética construtivista noções e conceitos sofrem desgaste, perdem significação, são desconstruídos e reconstruídos, ou desaparecem. Os exemplos a seguir apresentados, a partir de análises de Barroso (2018), ilustram a flutuação de noção para conceito nos usos do termo soberania:

A princípio, nenhum Estado se atreveria a uma agressão à soberania da Islândia. O país não dispõe de capacidade militar efetiva, mas adquiriu bastante respeito e, com isso, Estados aliados.

A independência da Catalunha é um desejo simbólico, cultural. A Catalunha não apresenta capacidade econômica e militar para garantir a soberania da comunidade.

A soberania da Grécia foi facilmente neutralizada devido à dependência econômica, financeira e monetária do país em relação ao resto do mundo econômico europeu.

No Brasil, quando se menciona Amazônia, muitos brasileiros sentem uma vaga inquietação acerca da soberania, surgindo de imediato questionamentos sobre a capacidade militar e do Estado de controlar fronteiras, florestas; inclusive no estatuto mitológico, dos segredos e riquezas que possam estar escondidos na floresta Amazônica, que ainda haverão de ser desvendados e encontrados...

Na questão de soberania sobre a Antártica, quais os critérios para que tais ou quais países tenham ou não direito a bases e instalações secretas de grande porte.

Igualmente na atmosfera, que condições de soberania determinam proteção contra a presença de dispositivos tangíveis e intangíveis que possam monitorar, interferir, e mesmo condicionar a vida de uma sociedade, nas 
diferentes formas de expressão, e.g., na defesa, na segurança internacional, na vida cotidiana dos indivíduos, em seu habitat, etc.

Para um Brasil soberano, quais os determinantes de autonomia científica e tecnológica.

As flutuações termo-noção-conceito de soberania podem ser usadas finalmente para indicar os sentidos de interpretação da História enquanto disciplina.

Podem ser ainda empregadas, no âmbito dos Estudos Estratégicos, para revigorar debates sobre posicionamentos do Estado brasileiro.

\section{Referências}

AGAMBEN, G. Homo Sacer: o poder soberano e a vida nua. Belo Horizonte: Editora UFMG. 2007.

ANDREW, E. Jean Bodin on sovereignty. Republics of Letters: A Journal for the Study of Knowledge, Politics, and the Arts, v. 2, n. 2, p. 73-84, 2011. Disponível em: $<$ https://arcade.stanford.edu/sites/default/files/article_pdfs/roflv02i02_Andrew_0 60111_0.pdf>. Acesso em: set. 2018

BARROS, José D'Assunção. Os Conceitos - seus usos nas ciências humanas. Petrópolis: Vozes, 2016.

BARROSO, C. M. A Filosofia da Stoa: as teses de Zenão e Cleanthes. Rio de Janeiro: 7 Letras, 2019.

BARROSO, C. M. As 3 estruturas. Rio de Janeiro: Edições Arca do Atlântico, 2012.

BARROSO, C. M. As 3 Estruturas - Estudos sobre a Forma Imperial do Capitalismo Financeiro no Séc. XXI. Rio de Janeiro: Grupo Domiciliar de Estudos Filosóficos, 2018.

BERGE, D. O logos heraclítico: introdução ao estudo dos fragmentos. Rio de Janeiro: Instituto Nacional do Livro, 1969.

BOBBIO, N. A teoria das formas de governo. Brasília: Editora Universidade de Brasília, 1980.

BODIN, J. Les six livres de la République. Paris: Jaques du Pois. 1583. Disponível em: 
Universidade Federal Fluminense

Instituto de Estudos Estratégicos

$<\mathrm{https}$ ://books.google.pt/books?id=XSE8AAAAcAAJ\&printsec=frontcover\&hl=pt -PT\&source=gbs_atb\#v=onepage\&q\&f=false $>$. Acesso em: set. 2018

BODIN, J. Os Seis Livros da República. Livro Primeiro. São Paulo: Ícone, 2011.

COMPSTON, H. W. The network of global corporate control: Implications for public policy. Business and Politics, v. 15, n. 3, p. 357-379, 2013. Disponível em: <http://orca.cf.ac.uk/49036/>. Acesso em: set. 2018.

DREIFUSS, R. A. A internacional capitalista. Rio de Janeiro : Espaço e Tempo, 1987.

DREIFUSS, R. A. "Corporações estratégicas e Estados nacionais: os protagonistas do grande jogo. In: MINEIRO, A. S; ELIAS, L. A; BENJAMIN, C. (Org.) Visões da crise. Rio de Janeiro: Contraponto, 1998, p. 25-31.

DREIFUSS, R. A. Transformações: matrizes do Século XXI. Petrópolis: Vozes, 2004.

FIGUEIREDO, E. L. Estudos Estratégicos como área de conhecimento científico. Revista Brasileira de Estudos de Defesa, v. 2, n. 2, p. 107-128, 2015.

FOUCAULT, M. Histoire de la sexualité. 1. La volonté de savoir. Paris: Gallimard, 1976.

GEERTZ, C. What is a state if it is not a sovereign? Reflections on politics in complicated places. Current Anthropology, v. 45, n. 5, dez. 2004.

GLATTFELDER, J. B. Ownership networks and corporate control: mapping economic power in a globalized world. 2010. 238f. Tese (Doutorado) - Chair of Systems Design", Department of Management Technology and Economics, Zurique, Suíça, ETH Zurich, 2010. Disponível em: <http://ecollection.library.ethz.ch/eserv/eth:2007/eth-2007-02.pdf>. Acesso em: set. 2018.

HAAS, E. Letter to the Editor. Journal of Common Market Studies, v. 8, n. 1, p. 70, set. 1969 .

HAN, B-C. Psicopolítica - o neoliberalismo e as novas técnicas de poder. $7^{\mathrm{a}}$ Ed. Belo Horizonte: Âyiné, 2020.

HANSEN, T.B.; STEPPUTAT, F. Sovereignty Revisited. The Annual Review of Anthropology, v. 35, p. 295-315, 2006. Disponível em:

$<$ https://www.annualreviews.org/doi/abs/10.1146/annurev.anthro.35.081705.12 3317>. Acesso em: jan. 2019. 
HOBBES, T. Leviatã ou matéria, forma e poder de um estado eclesiástico e civil. Coleção Os Pensadores. São Paulo: Abril Cultural, 1983.

HUDSON, M. Europe's transition from social democracy to oligarchy. Disponível em: <https://michael-hudson.com/2011/12/europes-transition-fromsocial-democracy-to- oligarchy/>. Acesso em: dez. 2018.

KOSELLECK, R. Estratos do tempo: estudos sobre história. Rio de Janeiro: Contraponto: PUC-Rio, 2014.

KOSELLECK, R. História de Conceitos. Rio de Janeiro: Contraponto, 2020.

KRASNER, J. D. Think Again: Sovereignty. Washington: Foreign Policy, November 20, 2009. Disponível em:

$<$ https://foreignpolicy.com/2009/11/20/think-again-sovereignty/\#>. Acesso em: jan. 2021.

LYON, D. Cultura da vigilância: envolvimento, exposição e ética na modernidade digital. In: BRUNO, F. et al. (Org.). Tecnopolíticas da vigilância: perspectivas da margem. São Paulo: Boitempo, 2018, p. 153-179.

MBEMBE, A. Necropolítica. São Paulo: N-1 Edições. 2018.

PERKINS, J. Confessions of an economic hit man. New York: Plume, 2006.

RISCAL, S. A. O conceito de soberania em Jean Bodin: um estudo do desenvolvimento das ideias de administração pública, governo e estado no século XVI. 2001. 537f. Tese (Doutorado em Educação). Faculdade de Educação, Universidade Estadual de Campinas, Campinas, São Paulo, 2001.

SANTOS, J. C. Fronteiras culturais. Revista da Escola Superior de Guerra, Rio de Janeiro, v. 31, n. 62, p. 150-170, jan./jul./2016.

SHINODA, H. Conflicting notions of national and constitutional sovereignty in the discourses of political theory and international relations: a genealogical perspective. 1997. 314f. (Doutorado em Filosofia) London School of Economics and Political Science, University of London, Londres, 1997. Disponível em: <http://etheses.Ise.ac.uk/2481/1/U615430.pdf>. Acesso em: set. 2018.

WEBER, C. Simulating sovereignty: intervention, the state and symbolic exchange. Cambridge: Cambridge University Press, 1995.

VERNANT, J-P. As origens do pensamento grego. Rio de Janeiro: Difel, 2004. 
VIEGAS, L. H. T; BOMTEMPO, J. V. How are radical innovations developed? an analytical framework to examine radical innovations based on the Values of Cohesion approach. In: DRUID12 Innovation and Competitiveness: dynamics of organizations, industries, systems and regions, 2012, Copenhagen. Anais eletrônicos...Copenhagen: DRUID Society, 2012. Disponível em:

<http://druid8.sit.aau.dk/acc_papers/mup0xvs9xjc2916f5dr6bh2eu3y4.pdf>. Acesso em: ago. 2013.

VITALI S.; GLATTFELDER J.B.; BATTISTON S. The network of global corporate control. PLoS One, v. 6, n. 10: e25995, 2011. Disponível em: <http://journals.plos.org/plosone/article?id=10.1371/journal.pone.0025995>. Acesso em: fev. 2016.

ZUBOFF, S. Big Other: capitalismo da vigilância e perspectivas para uma civilização da informação. In: BRUNO, F et al. (Org.). Tecnopolíticas da vigilância: perspectivas da margem. São Paulo: Boitempo, 2018, p. 17-68.9 